\title{
Is evidence-based practice a sinking ship?
}

\author{
Lisa A Harvey \\ University of Sydney, Australia \\ E-mail: spinalcord@iscos.org.uk
}

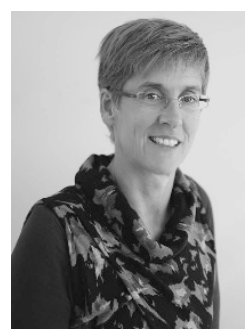

Surely it is not the job of an editor to be directing readers to other journals! That would be like a radio broadcaster telling listeners to tune into another channel, or to a company director telling consumers to purchase another product. However, this Editorial is going to do just that. I am going to recommend that the readers of Spinal Cord peruse another journal: The Journal of Clinical Epidemiology. (Please don't tell our publishers, this is between just you and me). The reason for directing you to this journal is because it has published a special issue in salute of David Sackett: the father of evidence-based practice (EBP), who died last year. ${ }^{1}$ This issue of The Journal of Clinical Epidemiology contains interesting and controversial papers about EBP. However, the paper which caught my eye was written by John Ioannidis. It is titled—"Hijacked evidence-based medicine: stay the course and throw the pirates overboard".

Who are the pirates that Ioannidis would have thrown overboard? More importantly, how are they hijacking EBP? Ioannidis argues that the 'pirates' are those who delight in finding any small nuance or deficiency in EBP that can be used to discredit the movement (to sink the ship of EBP). A common criticism is that EBP only cares about estimates of population-based averages and that these estimates are of little relevance because 'we are all individual' (as so famously stated in one of the Monty Python comedies). This criticism always takes me by surprise because of course we and our patients are all individuals, and of course very few patients are going to behave like the population-based estimates EBP strives to provide: some will do better and others will do worse.

Sackett never argued that we should only be driven by estimates of population-based averages. To the contrary, he was a strong advocate of the importance of combining this information with clinicians' and patients' perspectives, experiences and priorities. He defined EBP as 'integrating individual clinical expertise with the best available external clinical evidence from systematic research' (page 71). ${ }^{3}$ He was, nonetheless, a champion of the use of high quality external evidence to support clinical decision making.

Sackett's push for high quality external evidence was primarily based around the concern to avoid bias when assessing treatment effectiveness. That is why he advocated reliance on randomised controlled trials. In recent years randomised controlled trials have come under a sustained attack. The strongest attacks have been launched by those who are unhappy with the findings of clinical trials. When new treatments that initially looked promising, or when old treatments that we have all faithfully administered, fail to deliver, we tend to question the methodology rather than question the treatment. We criticise randomised controlled trials and EBP and search for other methodologies that are more likely to give us the answers we expect or want. Unfortunately, alternative methodologies are always inferior and vulnerable to bias.

Others criticise EBP because it fails to quantify the possibility of harm, identify subgroups of responders, and individualise medicine. Ioannidis states that:

“... rigorous evidence-based approaches show that often information on harms is limited, unreliable, and fragmented [6,7]; subgroup claims are spurious, false, and non-reproducible [8-10]; and individualizing medicine through personalized, precision, predictive, and other p-medicine is mostly a beautiful fairy tale [11-13]." (page 12).

But importantly he goes on to say:

"These are not EBM's faults. Conversely, EBM offers the tools to detect and fix these problems." (page 12).

We all want to find effective treatments and improve the lives of people with SCI. However, we won't get there unless we 'throw the pirates overboard'. We need to open our minds to the possibility that not all is as it appears. Until we become impartial scientists who are very aware of our own biases, we will continue to blame EBP when it fails to deliver. We need to keep the EBP ship afloat. It is our best hope for providing high quality and effective care to people with SCI.

\section{ANNOUNCEMENT}

Spinal Cord is pleased to announce the launch of two new prizes that we will be awarded to authors each year:

1. Winner of the 2016 Readers' Choice from all papers published in 2016 is: Dr P Boadas-Vaello, S Castany, J Homs, B Álvarez-Pérez, M Deulofeu and E Verdú. for Neuroplasticity of ascending and descending pathways after somatosensory system injury: reviewing knowledge to identify neuropathic pain therapeutic targets 2016; 54: 330-340.

2. Winner of the 2016 Readers' Choice for original research papers published in 2016 is: Prof Dr H E M Marei, A Althani, S Rezk, A Farag, S Lashen, N Afifi, A Abd-Elmaksoud, R Pallini, P Casalbore, C Cenciarelli and T Caceci. for Therapeutic potential of human olfactory bulb neural stem cells for spinal cord injury in rats 2016; 54: 785-797.

These awards are determined by the number of downloads in the 6 months following publication. This excludes any papers authored by the Editor-in-Chief or Associate Editors.

1 Knottnerus JA, Tugwell P. Evidence-based medicine: achievements and prospects. J Clin Epidemiol 2017; 84: 1-2.

2 loannidis JPA. Hijacked evidence-based medicine: stay the course and throw the pirates overboard. J Clin Epidemiol 2017; 84: 11-13.

3 Sackett DL, Rosenberg WMC, Gray JAM, Haynes RB, Richardson WS. Evidence based medicine: What it is and what it isn't. It's about integrating individual clinical expertise and the best external evidence. BMJ 1996; 312: 71-72.

Spinal Cord (2017) 55, 885; doi:10.1038/sc.2017.106 